\title{
2 An Optimised GAS-pharyngeal cell biofilm model
}

3 Heema K. N. Vyas ${ }^{1,2}$, Jason D. McArthur ${ }^{2}$, Martina L. Sanderson-Smith ${ }^{1,2^{*}}$

41 Illawarra Health and Medical Research Institute, Wollongong, New South Wales, Australia.

52 School of Chemistry and Molecular Bioscience, Molecular Horizons, University of Wollongong,

6 Wollongong, New South Wales, Australia.

7 * Correspondence: martina@uow.edu.au; Tel.: +61 242981935 (NSW, Australia)

8 Received: date; Accepted: date; Published: date

Abstract: Group A Streptococcus (GAS) causes 700 million infections and accounts for half a million deaths per year. Biofilm formation has been implicated in both pharyngeal and dermal GAS

11 infections. In vitro, plate-based assays have shown that several GAS M-types form biofilms, and 12 multiple GAS virulence factors have been linked to biofilm formation. Although the contributions 13 of these plate-based studies have been valuable, most have failed to mimic the host environment,

14 with many studies utilising abiotic surfaces. GAS is a human specific pathogen, and colonisation 15 and subsequent biofilm formation is likely facilitated by distinct interactions with host tissue surfaces. As such, a host cell-GAS model has been optimised to support and grow GAS biofilms of a variety of GAS M-types. Improvements and adjustments to the crystal violet biofilm biomass assay have also been tailored to reproducibly detect delicate GAS biofilms. We propose $72 \mathrm{~h}$ as an optimal growth period for yielding detectable biofilm biomass. GAS biofilms formed are robust and durable, and can be reproducibly assessed via staining/washing intensive assays such as crystal violet with

21 the aid of methanol fixation prior to staining. Lastly, SEM imaging of GAS biofilms formed by this model are resemblant of those previously found on excised tonsils of patients suffering chronic pharyngo-tonsillitis. Taken together, we outline an efficacious GAS biofilm pharyngeal cell model that can support long-term GAS biofilm formation, with biofilms formed closely resembling those seen in vivo. 


\section{Introduction}

human pathogen known to cause an array of infections ranging from mild infections of the skin and autoimmune sequelae [1]. GAS infections are a considerable burden on global healthcare systems with high rates of patient mortality and morbidity [2]. and in the skin lesions of GAS impetigo sufferers [3,4]. In vitro, it has been demonstrated that GAS biofilm formation is strain dependent. And among isolates of the same serotype, biofilm forming capacities are oftentimes found to differ considerably [5]. As highlighted in Table 1, in vitro platebased studies have implicated several GAS virulence factors (M protein, capsule, pili, SpeB, CovS, and quorum sensing peptides) in biofilm formation [6]. These findings have contributed substantially to our current understanding of GAS biofilms and their involvement in GAS pathogenesis and disease. However, much of this work has been conducted on abiotic surfaces (plastic, glass, and silicone). To date, few studies have used host matrix components like collagen, fibronectin, or fibrinogen as surface coatings for GAS biofilm studies [7-10]. Moreover, there is currently no methodology or protocol widely recognised as the gold standard for GAS biofilm formation. The variability among methods, and limited use of host factors in in vitro plate-based GAS biofilm models found in previous studies has been summarised in Table 1. This table highlights that only three in vitro plate-based studies utilising epithelial monolayers to grow and support GAS biofilms have been published. 
52 architecture of biofilms and their virulence gene expression, found to noticeably differ from that of

53 biofilms formed in vivo [10]. Moreover, tissue tropism displayed by differing GAS isolates towards

54 the throat and skin, which are vastly different epithelial landscapes and environments [11], will

55 influence GAS adherence, colonisation, and subsequent biofilm formation. Thus, the incorporation

56 of relevant host epithelial substratum, and an overall mimicking of the host environment should be

57 a consideration in GAS biofilm modelling.

58 Here, a GAS-pharyngeal cell biofilm model has been optimised to cultivate robust GAS biofilms

59 that can be used for a diverse set of GAS M-types. We also present optimised steps and tips for

60 increased biofilm integrity and reproducibility when performing staining assays like crystal violet.

61 This model has since been used to effectively assess the role pharyngeal cell surface glycans play in

62 GAS biofilm formation and clearly demonstrates the importance of mimicking the epithelial

63 environment in these studies [12]. 
Table 1. Examples of in vitro plate-based models used for the study of GAS biofilm formation.

\begin{tabular}{|c|c|c|c|c|c|c|}
\hline $\begin{array}{c}\text { Growth } \\
\text { Substratum }\end{array}$ & Time & $\begin{array}{c}\text { Media } \\
\text { conditions }\end{array}$ & Inoculum* & $\begin{array}{l}\text { emm- } \\
\text { type }\end{array}$ & Purpose of the study & Ref. \\
\hline Polystyrene & $\begin{array}{l}\text { Up to } \\
96 \mathrm{~h}\end{array}$ & $\begin{array}{l}\mathrm{C} \text { medium, } \\
23^{\circ} \mathrm{C}\end{array}$ & $0.1: 10$ & emm14 & $\begin{array}{l}\text { Biofilm forming abilities } \\
\text { of WT GAS compared to } \\
\text { mutants (capsule, } m g a \\
\text { virulence regulon, M- } \\
\text { protein, and } \operatorname{cov} R \text { ) }\end{array}$ & [10] \\
\hline Polystyrene & $24 \mathrm{~h}$ & $\begin{array}{c}\text { THY }-0.2 \% \text { yeast } \\
\text { supplemented } \\
\text { with } 0.5 \% \\
\text { glucose, } 37^{\circ} \mathrm{C}\end{array}$ & $1: 100$ & emm14 & $\begin{array}{l}\text { Microcolony-dependent } \\
\text { and } \\
\text {-independent biofilm } \\
\text { formation, with a focus } \\
\text { on the role of GAS } \\
\text { capsule }\end{array}$ & [13] \\
\hline $\begin{array}{l}\text { Glass and } \\
\text { cellular form } \\
\text { of fibronectin } \\
(\mathrm{cFn}) \text { coated } \\
\text { glass }\end{array}$ & 1 or $24 \mathrm{~h}$ & $\begin{array}{c}\text { Brain heart } \\
\text { infusion }(\mathrm{BHI}) \\
\text { and } \mathrm{THY}+0.2 \% \\
\text { yeast, } 37^{\circ} \mathrm{C}\end{array}$ & $\begin{array}{l}\text { Exponential } \\
\text { phase GAS }\end{array}$ & $\begin{array}{l}\text { emm1, } \\
28, \text { and } \\
41\end{array}$ & $\begin{array}{l}\text { Streptococcal collagen- } \\
\text { like protein-1 (Scl1) } \\
\text { binding wound } \\
\text { associated cFn (with extra } \\
\text { domain A) involvement } \\
\text { in biofilm formation }\end{array}$ & [7] \\
\hline $\begin{array}{l}\text { Human: } \\
\text { fibronectin, } \\
\text { fibrinogen, } \\
\text { laminin, } \\
\text { collagen } \\
\text { coated, or } \\
\text { uncoated } \\
\text { polystyrene }\end{array}$ & $\begin{array}{l}12 \text { to } \\
120 \mathrm{~h}\end{array}$ & $\begin{array}{c}\text { Luria Broth, } \\
\text { THY - 0.5\% } \\
\text { yeast, BHI, or } \\
\text { chemically } \\
\text { defined medium, } \\
\quad 37^{\circ} \mathrm{C}\end{array}$ & $\begin{array}{c}1 \times 10^{4} \\
\mathrm{CFU} / \mathrm{ml}\end{array}$ & $\begin{array}{c}\text { emm } 1,2, \\
3,6,12, \\
14,18, \\
28, \text { and } \\
49 \\
\\
\text { emm14 } \\
\text { and } \\
\text { emm } 18\end{array}$ & $\begin{array}{l}\text { Effect of coating with } \\
\text { human matrix } \\
\text { components in } \\
\text { potentiating biofilm } \\
\text { formation. } \\
\text { Investigating quorum } \\
\text { sensing signaling peptide } \\
\text { SilC in mediating biofilm } \\
\text { density and structure }\end{array}$ & [8] \\
\hline $\begin{array}{l}\text { Polylysine } \\
\text { coated glass } \\
\text { coverslips }\end{array}$ & $72 \mathrm{~h}$ & $\mathrm{C}$ medium, $37^{\circ} \mathrm{C}$ & $1: 10$ & & $\begin{array}{l}\text { Pilli involvement in } \\
\text { mature biofilm formation }\end{array}$ & \\
\hline $\begin{array}{l}\text { Pharyngeal: } \\
\text { Detroit } 562 \\
\text { monolayers }\end{array}$ & $2 \mathrm{~h}$ & THY, $37^{\circ} \mathrm{C}$ & $0.6 \mathrm{OD}_{600 \mathrm{~nm}}$ & emm 1 & $\begin{array}{l}\text { Pilli involvement in } \\
\text { initial adhesion and its } \\
\text { role in microcolony } \\
\text { development }\end{array}$ & [14] \\
\hline $\begin{array}{l}\text { Pharyngeal: } \\
\text { Detroit } 562 \\
\text { monolayers }\end{array}$ & $72 \mathrm{~h}$ & $\mathrm{THY}, 34^{\circ} \mathrm{C}$ & $1: 20$ & $\begin{array}{c}\text { emm } 1,3 \\
9,12 \\
44,53 \\
90,98 \\
108\end{array}$ & $\begin{array}{l}\text { Assessing the role of } \\
\text { pharyngeal cell surface } \\
\text { glycans in GAS biofilm } \\
\text { formation in the context } \\
\text { of GAS pharyngitis }\end{array}$ & [12] \\
\hline $\begin{array}{l}\text { Skin: SCC13 } \\
\text { monolayers } \\
\text { cells }\end{array}$ & $48 \mathrm{~h}$ & $\begin{array}{c}\text { THY- } 0.5 \% \text { yeast, } \\
34^{\circ} \mathrm{C}\end{array}$ & $\begin{array}{c}2 \times 10^{4} \\
\mathrm{CFU} / 0.5 \mathrm{~mL}\end{array}$ & $\begin{array}{l}\text { emm3 } \\
\text { and } \\
\text { emm6 }\end{array}$ & $\begin{array}{l}\text { Biofilms examined for } \\
\text { colonisation, virulence, } \\
\text { and genetic diversity }\end{array}$ & {$[15]$} \\
\hline
\end{tabular}

*Inoculums listed as ratios (bacteria: bacterial media), growth phase, or optical density. 


\section{Materials and Methods}

\section{GAS and culture conditions}

GAS strains used in this study (Table 2) are clinical GAS isolates, with each strain representative of a discrete GAS emm-type [16-18]. GAS was grown on horse blood agar (HBA) plates (Oxoid, UK) or Todd Hewitt agar supplemented with 1\% (w/v) yeast (THYA) (Difco, Australia). Static cultures of GAS were grown overnight in Todd Hewitt broth supplemented with $1 \%(w / v)$ yeast (THY). GAS was cultured, maintained, and biofilms formed at $34^{\circ} \mathrm{C}$ to mimic conditions more closely seen in the in vivo pharyngeal environment as described by Marks, et al. [19].

Table 2. GAS strains utilised in this study, their emm-types, and clinical source.

\begin{tabular}{cccc}
\hline M-type & Strain & Clinical source & Ref. \\
\hline M1 & 5448 & Invasive infection: Necrotising fasciitis and toxic shock & {$[18]$} \\
M12 & PRS-8 & Superficial infection: persistent Pharyngeal pus/sinusitis & {$[17]$} \\
M3 & 90254 & Invasive infection & {$[17]$} \\
M98 & NS88.2 & Invasive infection: Blood (bacteraemia) & {$[16]$} \\
M108 & NS50.1 & Superficial infection: Wound & {$[16]$} \\
\hline
\end{tabular}

Human pharyngeal cell culture conditions

Detroit 562, a human pharyngeal epithelial cell line (CellBank Australia, Australia), was cultured in Dulbecco's Modified Eagle Medium (DMEM) F12 (Invitrogen, Australia), supplemented with 2 mM L-glutamine (Gibco, Life Technologies, UK) and $10 \%(\mathrm{v} / \mathrm{v})$ heat inactivated foetal bovine serum (FBS) (Bovogen Biologicals, Australia) in cell culture flasks at $37^{\circ} \mathrm{C}, 5 \% \mathrm{CO}_{2}-20 \% \mathrm{O}_{2}$ atmosphere.

Pharyngeal cell monolayer formation

Detroit 562 pharyngeal cell monolayers form the substratum for GAS biofilm growth. An outline of the process and the monolayers formed is depicted in Fig. 1.

- The wells of a 96-well flat bottom cell culture microtiter plate (Greiner Bio-One, Germany) were coated with $50 \mu \mathrm{L}$ of $300 \mu \mathrm{g} / \mathrm{mL}$ Collagen I from rat tail (Gibco, Life Technologies, UK) prepared in pre-chilled, sterile $17.4 \mathrm{mM}$ acetic acid solution. The plate was incubated for $1 \mathrm{~h}$, $37^{\circ} \mathrm{C}, 5 \% \mathrm{CO}_{2}-20 \% \mathrm{O}_{2}$ atmosphere. 

suspension $\left(2 \times 10^{5}\right.$ cells $\left./ \mathrm{mL}\right)$ and cultured for $48 \mathrm{~h}$ (to achieve $\sim 95 \%$ confluency). paraformaldehyde (PFA) (w/v) for $20 \mathrm{~min}$. kept wet via submersion in $200 \mu \mathrm{L}$ of sterile PBS) until required for use.

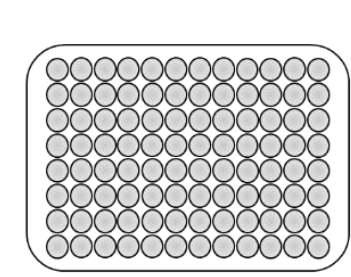

Coat wells with $50 \mu \mathrm{L}$ of collagen IV $(3 \mu \mathrm{g} / \mathrm{mL})$

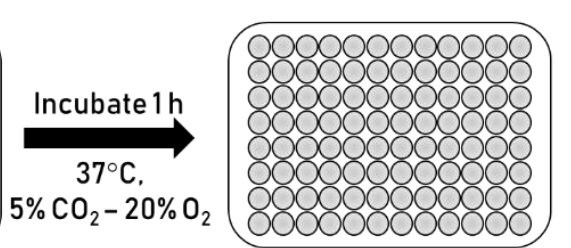

Remove excess collagen and seed wells with $150 \mu \mathrm{L}$ of $2 \times 10^{5}$ cells $/ \mathrm{mL}$ Detroit 562 cell suspension

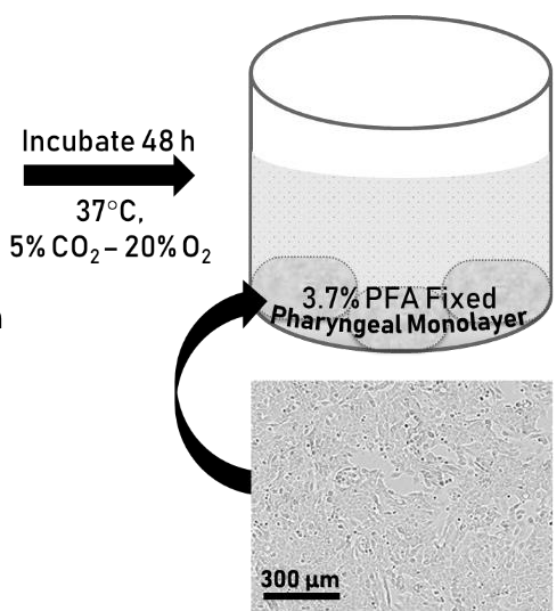

Achieving 95\% confluency

Figure 1. Schematic outlining the process of Detroit 562 pharyngeal cell monolayer formation. Schematic shows collagen coating, seeding with Detroit 562 pharyngeal cells, and finally an example well containing a 3.7\% PFA fixed $~ 95 \%$ confluent monolayer of Detroit 562 pharyngeal cells. Example monolayer image taken at 10x objective at the Incucyte.

GAS biofilm formation

- Wells containing pre-formed fixed Detroit 562 pharyngeal cell monolayers were seeded with $150 \mu \mathrm{L}$ of overnight GAS culture diluted 1:20 in THY-glucose (0.5\% glucose v/v) (THY-G). Wells containing $150 \mu \mathrm{L}$ sterile THY-G (no bacteria) served as media sterility controls and blanks.

- The plate was incubated for $2 \mathrm{~h}\left(34^{\circ} \mathrm{C}, 50 \mathrm{rpm}\right)$ to facilitate GAS interacting with and adhering to the pharyngeal cell monolayer substratum. 

subsequently assayed. Thus, it is advised (where possible) to grow biofilms in the inner-most wells of the plate, with wells not in use filled with $200 \mu \mathrm{L}$ of sterile water. dehydration of biofilm wells within the plate. interaction occurring between GAS-host cell surface structures at the $2 \mathrm{~h}$ point. Thus, this incubation time can be changed dependent on the nature of the study. bound cells, debris, and any waste. Note: GAS biofilms are quite delicate. against the wall of the well at an angle of $\sim 45^{\circ}$. replenish the THY-G media slowly and gradually (swapping out $50 \mu \mathrm{L}$ at a time). 
- Dried biofilms were then fixed with $150 \mu \mathrm{L}$ of $99 \%$ methanol for $15 \mathrm{~min}$. recommended. This prevents/reduces biofilm disruption/loss into the pipette tip.

- Biofilms were thoroughly air-dried and stained with $150 \mu \mathrm{L}$ of $0.2 \%$ crystal violet (w/v) (SigmaAldrich, USA) supplemented with $1.9 \%$ ethanol (v/v) for $10 \mathrm{~min}$ (RT, static). biofilm samples. $\mu \mathrm{L}$ of PBS.

- Crystal violet stain that had incorporated into the biofilm was re-solubilised upon the addition of $150 \mu \mathrm{L}$ of $1 \%$ sodium dodecyl sulphate (SDS) (w/v) (Sigma-Aldrich, USA).

- Plate was incubated for $10 \mathrm{~min}$ (RT, static).

- Biofilm biomass was quantified spectrophotometrically at OD540nm (SpectraMax Plus 384 microplate reader). on the Detroit 562 pharyngeal cell monolayers as these are all associated with GAS pharyngitis [1].

151 Preparation of biofilms for SEM was adapted from [20] with the following modifications. 

monohydrochloride, and $0.001 \%$ ruthenium red solution prepared in $0.1 \mathrm{M} \mathrm{HEPES}$ buffer $(\mathrm{pH}$ 7.3) $\left(30 \mathrm{~min}, 4^{\circ} \mathrm{C}\right)$.

- Following pre-fixation, biofilms were fixed in fixative solution $(2.5 \%$ glutaraldehyde and $0.001 \%$ ruthenium red prepared in 0.1 M HEPES buffer, $\mathrm{pH} 7.3)$ for $1.5 \mathrm{~h}\left(4^{\circ} \mathrm{C}\right)$ and washed twice in 0.1M HEPES buffer. distilled water (each 15 mins). from the biofilms before they were critical point dried (Leica CPD 030, Austria). and visualised using a JEOL JSM-7500 microscope (JEOL, Japan) at 500, 5000, and $15000 \mathrm{x}$ magnification. $5000 \times$ magnification.

174 USA). Datasets were compared using a student T-test, and a P-value of $\leq 0.05$ was considered 175 significant.

\section{Results}


181 GAS biofilms were assessed for their biofilm forming abilities on both a plastic substratum and monolayers.

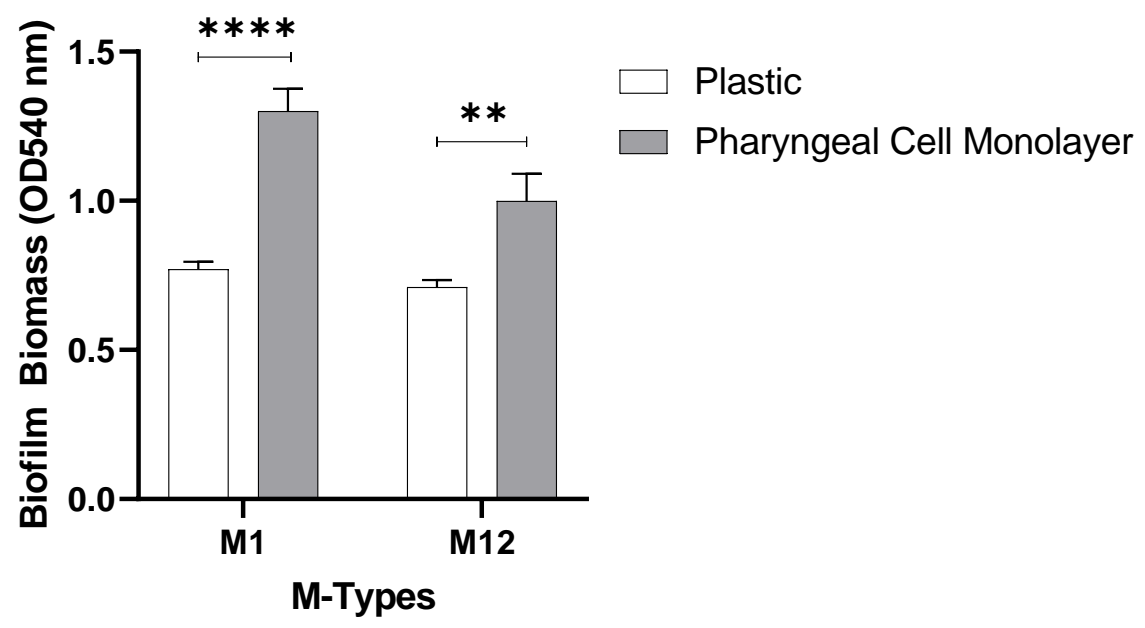
with concerns around reproducibility $[23,24]$. Reproducibility can be influenced by a biofilms overall durability and stability, especially during the wash steps [24]. As such, biofilms that are thinner and

Figure 2. M1 and M12 GAS were assessed for the ability to form biofilm on plastic and Detroit 562 pharyngeal cell monolayers. $48 \mathrm{~h}$ biofilms were formed and biofilm biomass ascertained via crystal violet staining. Monolayers with THY (no GAS biofilm) served as media sterility controls and background staining controls, with absorbance values subtracted from those of biofilm samples. Data represents mean $\pm \mathrm{SEM}^{* *}(\mathrm{P} \leq 0.01)$ and ${ }^{* * *}(\mathrm{P} \leq 0.0001) ; \mathrm{n}=3$ biological replicates, with 3 technical replicates each.

\section{Methanol fixation improves reproducibility of crystal violet staining on GAS biofilms}

Crystal violet assays were first described by Christensen, et al. [21] as a means of quantifying biofilm. Crystal violet has proven useful in that it detects biofilm in its entirety, staining a biofilms biomass which comprises live and dead cells, as well as EPS matrix. Taken together with its overall ease of use and relatively low cost it has since become a routinely used biofilm stain and detection method [22]. Despite these attributes, there are some drawbacks and limitations to crystal violet use, flimsier require further consideration of overall biofilm handling. Additional steps to the crystal 
violet assay can be implemented to ensure biofilm retention during the various washing, staining,

201 and de-staining steps of the assay.

In the current study, to minimise disruption and damage to the biofilm, biofilm plate layout/growth conditions and overall handling were optimised as outlined in the methods according to the following specifications; growing biofilms at the inner-most wells of a plate with unused wells filled with water to avoid dehydration; adjusting pipetting volume for media removal to account for dehydration during incubations; placing the plate inside a container containing additional water to reduce media evaporation from the wells; gradual media changes $(50 \mu \mathrm{L}$ at a time, as opposed to the entire $150 \mu \mathrm{L}$ ) etc. Furthermore, to improve the durability of the biofilms during crystal violet assaying, $48 \mathrm{~h}$ biofilms grown on the Detroit 562 pharyngeal monolayers were either fixed with methanol or left unfixed and assessed for biofilm biomass (Fig. 3).

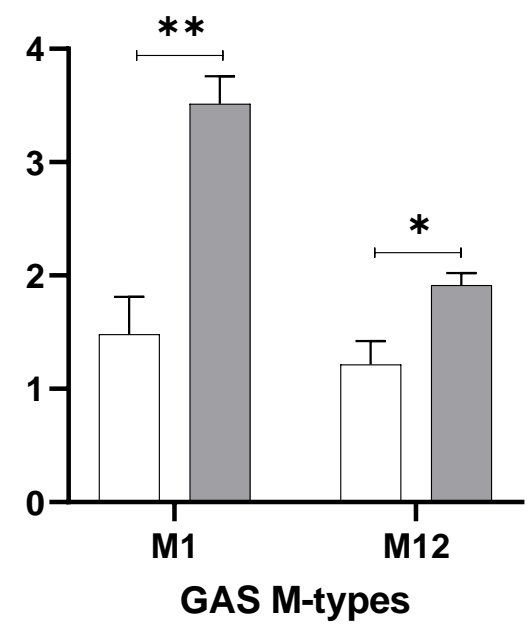

\section{Non-methanol Fixed}

Methanol Fixed cell monolayer after $2 \mathrm{~h}$ incubation. Biofilm biomass was ascertained via crystal violet staining. Monolayers with THY (no GAS biofilm) served as media sterility controls and background staining controls, with absorbance values subtracted from those of biofilm samples. Data represents mean \pm $\mathrm{SEM},{ }^{*}(\mathrm{P} \leq 0.05)$ and ${ }^{* *}(\mathrm{P} \leq 0.01) ; \mathrm{n}=3$ biological replicates, with 3 technical replicates each. 
After optimising the crystal violet assay for GAS biofilms, M1 and M12 GAS biofilm formation

biofilm biomass at $72 \mathrm{~h}$ was also greater than the biofilm biomass formed previously at $48 \mathrm{~h}$.

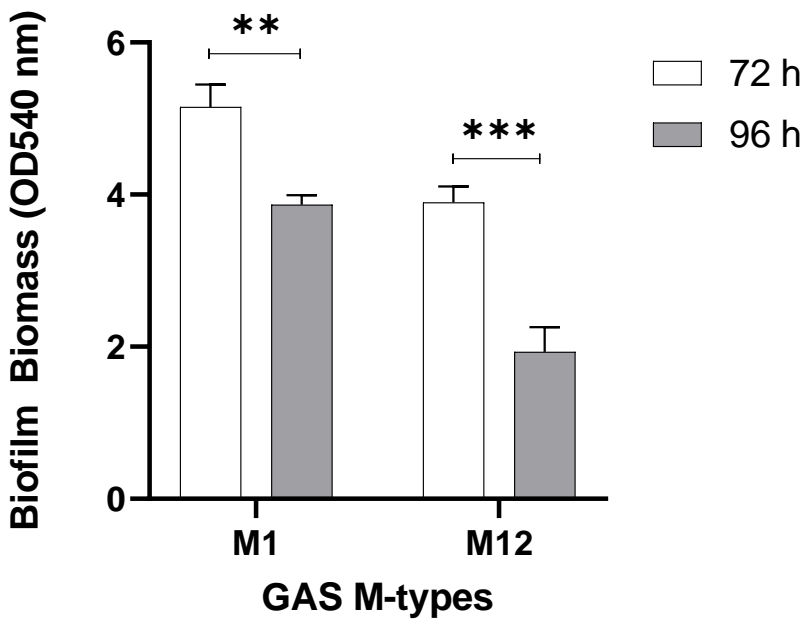

Figure $4.72 \mathrm{~h}$ is an optimal period for GAS biofilm formation. M1 and M12 were assessed for GAS biofilm formation at 72 and $96 \mathrm{~h} .72 \mathrm{~h}$ yielded significantly more biofilm than $96 \mathrm{~h}$. Biofilm biomass was determined via crystal violet staining. Monolayers with THY (no GAS biofilm) served as media sterility controls and background staining controls, with absorbance values subtracted from those of biofilm samples. Data represents mean \pm SEM, ${ }^{* *}(\mathrm{P} \leq 0.01)$ and ${ }^{* *}(\mathrm{P} \leq 0.001) ; \mathrm{n}=3$ biological replicates, with 3 technical replicates each. 


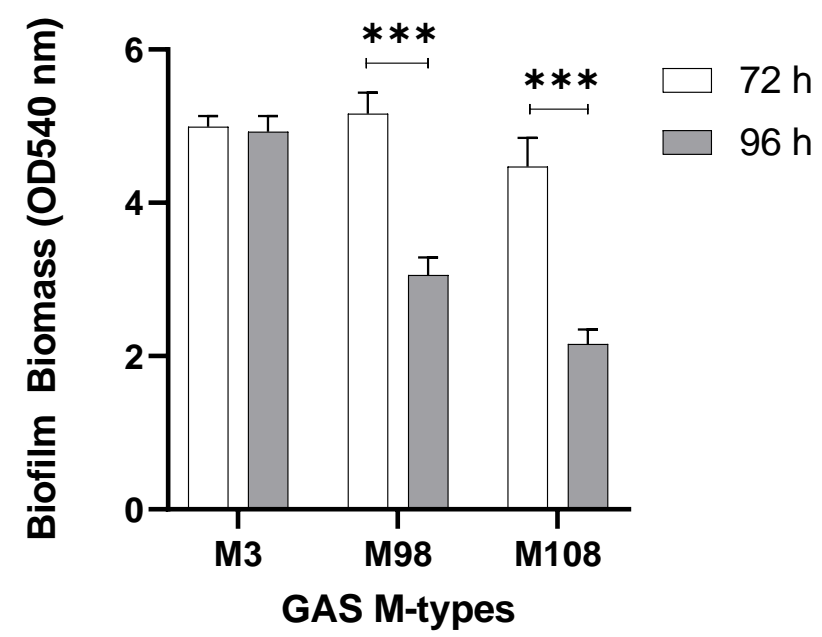

Figure 5. Assessing the utility of the optimised methodology on additional GAS M types (M3, 98, and 108). Biofilm biomass was determined via crystal violet staining. Monolayers with THY (no GAS biofilm) served as media sterility controls and background staining controls, with absorbance values subtracted from those of biofilm samples. Data represents mean $\pm \mathrm{SEM},{ }^{* *}(\mathrm{P} \leq 0.01)$ and ${ }^{* * *}(\mathrm{P} \leq 0.001)$; $\mathrm{n}=3$ biological replicates, with 3 technical replicates each.

M1 and M12, as well as an M3 strain also implicated in GAS pharyngitis [1] was imaged via

SEM. Specifically, $72 \mathrm{~h}$ GAS biofilms grown on Detroit 562 pharyngeal cell monolayers were visually

observed by SEM for their overall biofilm architecture, arrangement, and structure. M1, M12, and M3

247 GAS biofilms show cocci chains arranged in three-dimensional aggregated communities atop the

248 Detroit 562 pharyngeal cell monolayers (Fig 6). However, M1 (Fig. 6 A and B) and M3 (Fig. 6 E and

249 H) biofilms were found to arrange in tightly packed aggregates of cocci chains on the Detroit 562

250 monolayers, whereas M12 biofilms were more loosely arranged atop of the monolayers (Fig. $6 \mathrm{C}$ and

251 D). All biofilms produced noticeable EPS that was found closely associated with the cocci chains (Fig

252 6. B, D, and F). Detroit 562 pharyngeal cell monolayers (without biofilm) are also shown (Fig 6. G and

253 H) depicting the pharyngeal cells arranged in confluent monolayers, with pharyngeal cells displaying

254 their cell surface projections. 


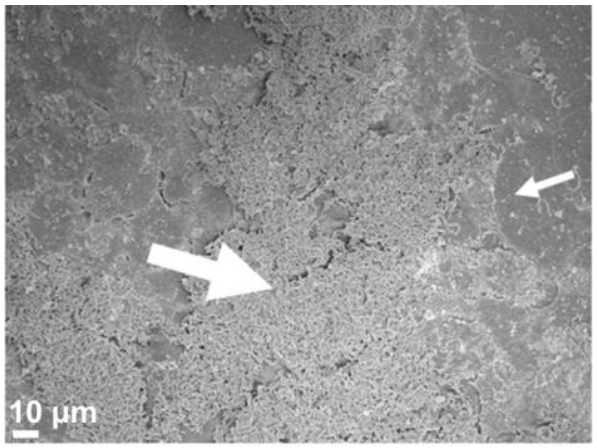

(A)

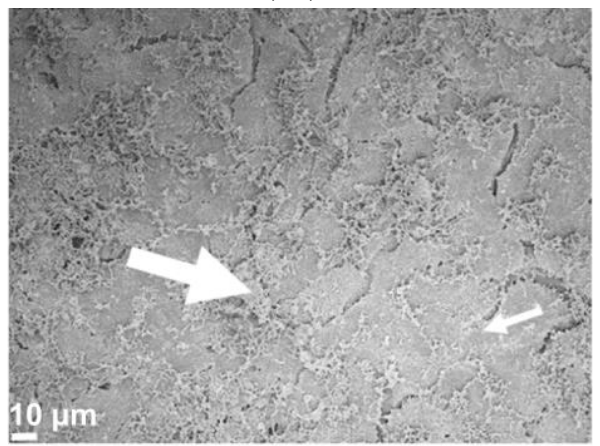

(C)

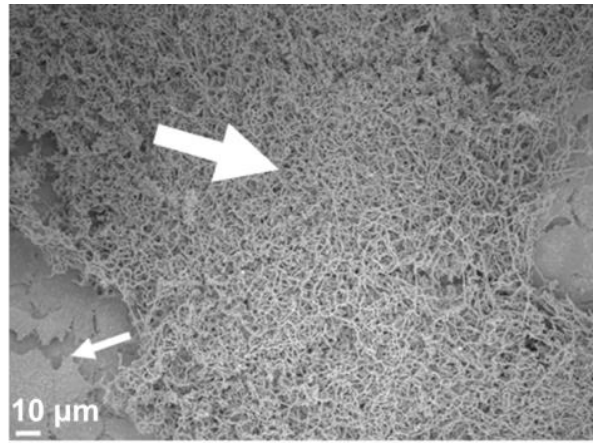

(E)

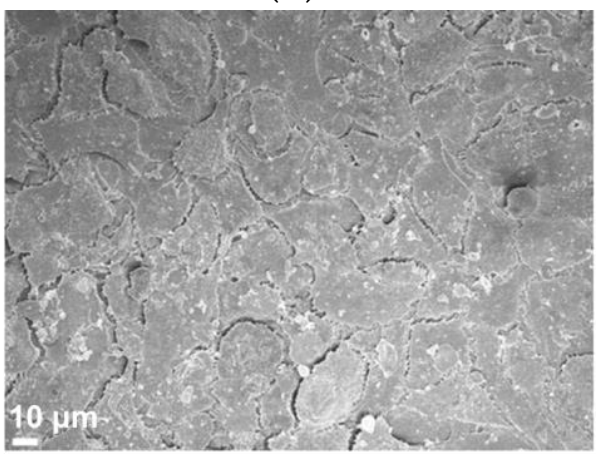

(G)

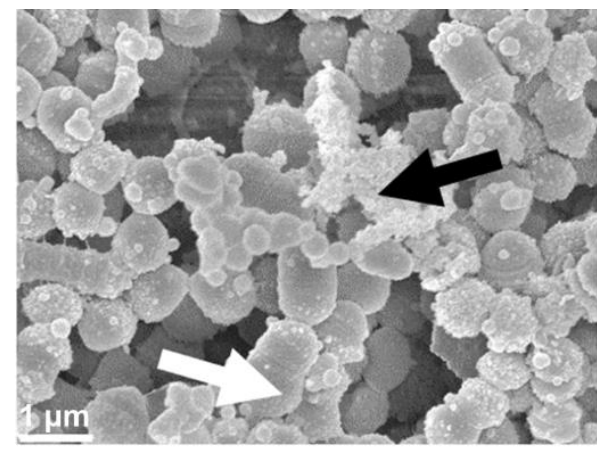

(B)

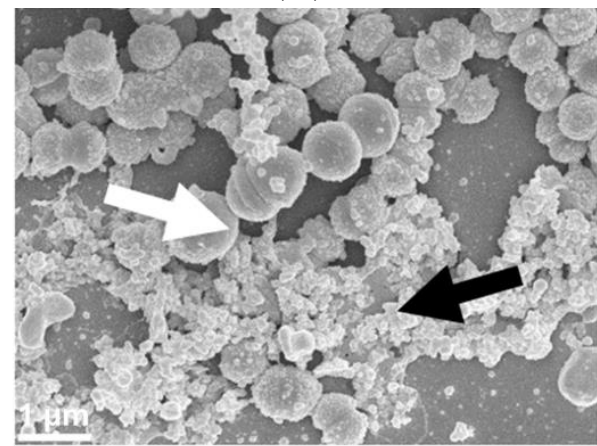

(D)

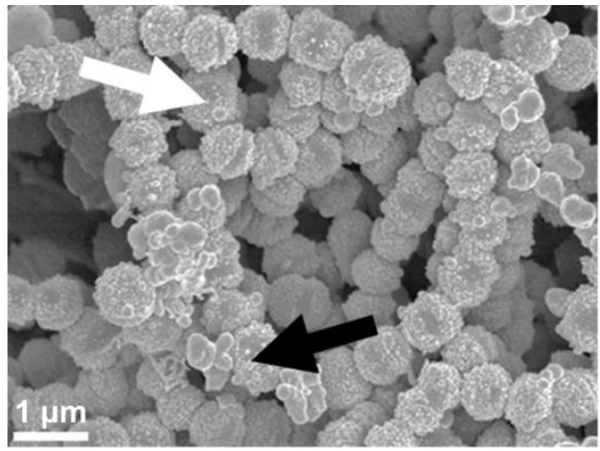

(F)

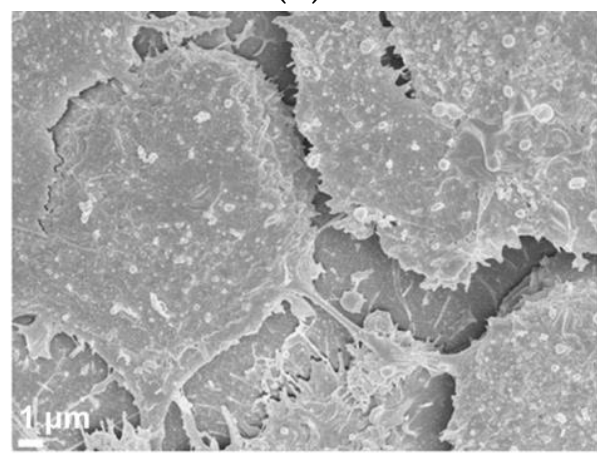

(H)

Figure 6. Representative $72 \mathrm{~h} \mathrm{M1} \mathrm{(A} \mathrm{and} \mathrm{B),} \mathrm{M12} \mathrm{(C} \mathrm{and} \mathrm{D),} \mathrm{and} \mathrm{M3} \mathrm{(E} \mathrm{and} \mathrm{F)} \mathrm{GAS} \mathrm{biofilms}$ visualised by scanning electron microscopy at 500 and $15000 \times$ magnification. GAS biofilms show chained cocci (white arrows) arranged into three dimensional aggregated structures with EPS (black arrows) upon the Detroit 562 monolayers (smaller white arrows). Detroit 562 monolayers (without biofilm) (G and $\mathbf{H}$ ) were also imaged at 500 and $5000 \times$ magnification. Images represent 3 biological replicates, with 3 technical each. 


\section{Discussion}

GAS is a human pathogen, which when in the host is reliant on several host factors to prompt

263 and facilitate dynamic and unique interactions necessary for successful colonisation and persistence.

264 Most in vitro plate-based GAS biofilm models used previously do not mimic the host environment.

265 Moreover, the use of an epithelial substratum for growth is rare. Given the importance of the GAS-

266 host tissue interface in mediating the earlier stages of GAS association and adherence, it is likely that

267 these interactions are also crucial for various stages of subsequent biofilm formation and

268 establishment within the host. Thus, modelling in the absence of host factors and/or relevant host

269 epithelial substratum in in vitro plate-based biofilm models may result in biofilms that do not

270 accurately represent the GAS biofilms in vivo. Here we report an optimised method for GAS biofilm

271 formation using Detroit 562 pharyngeal cell monolayers as a model for GAS-host interaction.

272 In the current study, an optimised method for forming GAS biofilm on fixed pharyngeal cell

273 monolayers has been developed. Despite Detroit 562 pharyngeal cells not being a primary cell line,

274 they are suitable for this model for numerous reasons; i) the cell line is derived directly from human

275 pharyngeal tissue, a site which GAS readily colonises, ii) retention of surface structures after culturing

276 for adherence (e.g. carbohydrate epitopes) representative of native pharyngeal cells has been noted,

277 and iii) they have been used extensively in planktonic GAS adherence assays [11,25-28]. Overall,

278 utilisation of pharyngeal epithelial substratum within this model aimed to better recreate the host

279 environment than in most of the in vitro models used previously.

280 GAS biofilm biomass increased significantly when grown on fixed Detroit 562 pharyngeal cell

281 monolayers, when compared to biofilm grown on abiotic plastic substratum. This highlights the

282 difference in biofilm potentiation, as a direct result of substratum for biofilm growth. This supports

283 the utility for GAS biofilm modelling to include epithelia as a substratum for biofilm growth over an

284 abiotic plastic surface. Whilst various staining techniques have been developed to assess biofilm

285 biomass, crystal violet staining remains one of the most common techniques within the field. Here,

286 we propose optimisation of this method at the biofilm formation steps preceding crystal violet 
staining, as well as additional considerations required during the crystal violet assay that are tailored washing steps. In turn, reducing error, and increasing reproducibility.

Broth grown GAS is inherently toxic to epithelial cells, as such, there have previously been no models that explore or support long-term GAS biofilm-epithelia co-culture in a plate-based model [15]. Here, we show that fixed pharyngeal cell monolayers support GAS biofilm formation beyond $48 \mathrm{~h}$. However, of the three time points assessed, $72 \mathrm{~h}$ is the most optimal biofilm growth period for yielding the greatest biofilm biomass for M1, M12, M98, and M108 GAS. Biofilm biomass was seen to diminish at $96 \mathrm{~h}$, likely resulting from partial disintegration of biofilm. This may be indicative of a mature or older biofilm reaching the final step of the biofilm life cycle - dispersal. Dispersal is thought to be triggered by nutrient exhaustion at the site, which in a host enables bacteria to shift to a motile planktonic state for biofilm re-establishment elsewhere $[8,29,30]$. These results agreed with a previous study of M6 and M49 biofilms grown on abiotic plastic well surfaces of a 96 well plate-based system,

303 whereby biofilms had greater biomass at $72 \mathrm{~h}$, and exhibited partial disintegration at $96 \mathrm{~h}$ with 304 authors attributing this to the age of the biofilm and nutrient limitation [8]. biofilm atop the Detroit 562 pharyngeal cell monolayers. Cocci chains, typical of GAS, can be seen arranged in three dimensional aggregated structures coated in EPS matrix for all three M-types.

308 Importantly, biofilms formed in this GAS-pharyngeal epithelial cell model appear similar to SEM 309 images captured of GAS biofilms found at the surface of tonsils removed from patients with recurrent 310 GAS tonsillo-pharyngitis [3].

311 Here we demonstrate an efficacious GAS biofilm-pharyngeal cell model that can support long312 term biofilm formation, with biofilms formed resembling those seen in vivo. This model has since 
interactions exert on biofilm formation.

Author Contributions statement: Conceptualisation, H.K.N.V, M.L.S-S, and J.D.M; methodology, H.K.N.V; formal analysis, H.K.N.V; investigation, H.K.N.V; resources, M.L.S-S, and J.D.M; data curation, H.K.N.V; writing-original draft preparation, H.K.N.V; writing-review and editing, H.K.N.V, M.L.S-S, and J.D.M; visualisation, H.K.N.V; supervision, M.L.S-S, and J.D.M; funding acquisition, M.L.S-S and J.D.M. All authors have read and agreed to the published version of the manuscript.

Funding: This work was funded by an NHMRC Project Grant APP1143266 and Molecular Horizons to M.L.S-S. H.K.N.V is a recipient of an Australian Postgraduate Award.

Acknowledgments: The authors acknowledge the valuable assistance of staff at the UOW Electron Microscopy Centre for their help with the specimen preparation and the operation of the JEOL 7500 SEM. We also thank

\section{Additional Information}

Competing interests' statement: The authors declare no conflict of interest.

\section{$330 \quad$ References}

331 1. Walker, M.J.; Barnett, T.C.; McArthur, J.D.; Cole, J.N.; Gillen, C.M.; Henningham, A.;

2. Carapetis, J.R.; Steer, A.C.; Mulholland, E.K.; Weber, M. The global burden of group A

3. Roberts, A.L.; Connolly, K.L.; Kirse, D.J.; Evans, A.K.; Poehling, K.A.; Peters, T.R.; Reid, S.D.

5. Baldassarri, L.; Creti, R.; Recchia, S.; Imperi, M.; Facinelli, B.; Giovanetti, E.; Pataracchia, M.; Sriprakash, K.S.; Sanderson-Smith, M.L.; Nizet, V. Disease Manifestations and Pathogenic Mechanisms of Group A Streptococcus. Clinical Microbiology Reviews 2014, 27, 264-301, doi:10.1128/CMR.00101-13. Detection of group A Streptococcus in tonsils from pediatric patients reveals high rate of asymptomatic streptococcal carriage. BMC Pediatrics 2012, 12, 3-3, doi:10.1186/1471-2431-12-

4. Akiyama, H.; Morizane, S.; Yamasaki, O.; Oono, T.; Iwatsuki, K. Assessment of Streptococcus pyogenes microcolony formation in infected skin by confocal laser scanning microscopy. Journal of Dermatological Science 2003, 32, 193-199, doi:http://dx.doi.org/10.1016/S09231811(03)00096-3. Alfarone, G.; Orefici, G. Therapeutic failures of antibiotics used to treat macrolide-susceptible Streptococcus pyogenes infections may be due to biofilm formation. Journal of Clinical Microbiology 2006, 44, 2721-2727.

6. Vyas, H.K.N.; Proctor, E.-J.; McArthur, J.; Gorman, J.; Sanderson-Smith, M. Current Understanding of Group A Streptococcal Biofilms. Current Drug Targets 2019, 20, 982-993, doi:http://dx.doi.org/10.2174/1389450120666190405095712.

7. Oliver-Kozup, H.; Martin, K.H.; Schwegler-Berry, D.; Green, B.J.; Betts, C.; Shinde, A.V.; Van 
biofilm formation by targeting the extra domain A-containing variant of cellular fibronectin expressed in wounded tissue. Mol Microbiol 2013, 87, 672-689, doi:10.1111/mmi.12125.

8. Lembke, C.; Podbielski, A.; Hidalgo-Grass, C.; Jonas, L.; Hanski, E.; Kreikemeyer, B. Characterization of biofilm formation by clinically relevant serotypes of group A streptococci. Applied and environmental microbiology 2006, 72, 2864-2875.

9. Sugareva, V.; Arlt, R.; Fiedler, T.; Riani, C.; Podbielski, A.; Kreikemeyer, B. Serotype- and strain- dependent contribution of the sensor kinase CovS of the CovRS two-component system to Streptococcus pyogenes pathogenesis. BMC Microbiology 2010, 10, 34, doi:10.1186/1471-2180-10-34.

10. Cho, K.H.; Caparon, M.G. Patterns of virulence gene expression differ between biofilm and doi:10.1111/j.1365-2958.2005.04786.x.

11. Bessen, D.E.; Lizano, S. Tissue tropisms in group A streptococcal infections. Future Microbiol 2010, 5, 623-638, doi:10.2217/fmb.10.28.

12. Vyas, H.K.N.; Indraratna, A.D.; Everest-Dass, A.; Packer, N.H.; De Oliveira, D.M.P.; Ranson,

13. Matysik, A.; Kline, K.A. $<$ em $>$ Streptococcus pyogenes $</$ em $>$ capsule promotes microcolonyM.; McArthur, J.D.; Sanderson-Smith, M.L. Assessing the Role of Pharyngeal Cell Surface Glycans in Group A Streptococcus Biofilm Formation. Antibiotics 2020, 9, 775, doi:https://doi.org/10.3390/antibiotics9110775.

14. Manetti, A.G.; Zingaretti, C.; Falugi, F.; Capo, S.; Bombaci, M.; Bagnoli, F.; Gambellini, G.;

15. Marks, L.R.; Mashburn-Warren, L.; Federle, M.J.; Hakansson, A.P. Streptococcus pyogenes

16. McKay, F.C.; McArthur, J.D.; Sanderson-Smith, M.L.; Gardam, S.; Currie, B.J.; Sriprakash, Bensi, G.; Mora, M.; Edwards, A.M., et al. Streptococcus pyogenes pili promote pharyngeal cell adhesion and biofilm formation. Mol Microbiol 2007, 64, 968-983, doi:10.1111/j.13652958.2007.05704.x. biofilm growth in vitro and in vivo and its role in colonization, virulence and genetic exchange. Journal of Infectious Diseases 2014, jiu058. K.S.; Fagan, P.K.; Towers, R.J.; Batzloff, M.R.; Chhatwal, G.S., et al. Plasminogen binding by group A streptococcal isolates from a region of hyperendemicity for streptococcal skin infection and a high incidence of invasive infection. Infection and immunity 2004, 72, 364-370, doi:10.1128/iai.72.1.364-370.2004.

17. Sanderson-Smith, M.; De Oliveira, D.M.P.; Guglielmini, J.; McMillan, D.J.; Vu, T.; Holien, J.K.; Henningham, A.; Steer, A.C.; Bessen, D.E.; Dale, J.B., et al. A Systematic and Functional Classification of Streptococcus pyogenes That Serves as a New Tool for Molecular Typing and Vaccine Development. The Journal of infectious diseases 2014, 210, 1325-1338, doi:10.1093/infdis/jiu260 \%J The Journal of Infectious Diseases.

18. Aziz, R.K.; Pabst, M.J.; Jeng, A.; Kansal, R.; Low, D.E.; Nizet, V.; Kotb, M. Invasive M1T1 group A Streptococcus undergoes a phase-shift in vivo to prevent proteolytic degradation of multiple virulence factors by SpeB. 2004, 51, 123-134, doi:10.1046/j.1365-2958.2003.03797.x. 
19. Marks, L.R.; Parameswaran, G.I.; Hakansson, A.P. Pneumococcal interactions with epithelial cells are crucial for optimal biofilm formation and colonization in vitro and in vivo. Infect Immun 2012, 80, 2744-2760, doi:10.1128/iai.00488-12.

20. Williams, D.L.; Bloebaum, R.D. Observing the biofilm matrix of Staphylococcus epidermidis ATCC 35984 grown using the CDC biofilm reactor. Microscopy and Microanalysis 2010, 16, $143-$ 152.

21. Christensen, G.D.; Simpson, W.; Younger, J.; Baddour, L.; Barrett, F.; Melton, D.; Beachey, E. Adherence of coagulase-negative staphylococci to plastic tissue culture plates: a quantitative model for the adherence of staphylococci to medical devices. Journal of clinical microbiology 1985, 22, 996-1006.

22. Wilson, C.; Lukowicz, R.; Merchant, S.; Valquier-Flynn, H.; Caballero, J.; Sandoval, J.; Okuom, M.; Huber, C.; Brooks, T.D.; Wilson, E., et al. Quantitative and Qualitative Assessment Methods for Biofilm Growth: A Mini-review. Res Rev J Eng Technol 2017, 6, http://www.rroij.com/open-access/quantitative-and-qualitative-assessment-methods-forbiofilm-growth-a-minireview-.pdf.

23. Pantanella, F.; Valenti, P.; Natalizi, T.; Passeri, D.; Berlutti, F. Analytical techniques to study microbial biofilm on abiotic surfaces: pros and cons of the main techniques currently in use. Annali di igiene : medicina preventiva e di comunita 2013, 25, 31-42, doi:10.7416/ai.2013.1904.

24. Azeredo, J.; Azevedo, N.F.; Briandet, R.; Cerca, N.; Coenye, T.; Costa, A.R.; Desvaux, M.; Di Bonaventura, G.; Hébraud, M.; Jaglic, Z., et al. Critical review on biofilm methods. Critical Reviews in Microbiology 2017, 43, 313-351, doi:10.1080/1040841X.2016.1208146.

25. Barthelson, R.; Mobasseri, A.; Zopf, D.; Simon, P. Adherence of Streptococcus pneumoniae to respiratory epithelial cells is inhibited by sialylated oligosaccharides. Infection and immunity 1998, 66, 1439-1444.

26. Frick, I.M.; Schmidtchen, A.; Sjobring, U. Interactions between M proteins of Streptococcus pyogenes and glycosaminoglycans promote bacterial adhesion to host cells. European journal of biochemistry 2003, 270, 2303-2311, doi:10.1046/j.1432-1033.2003.03600.x.

27. Ryan, P.A.; Juncosa, B. Group A streptococcal adherence. 2016.

28. Ryan, P.A.; Pancholi, V.; Fischetti, V.A. Group A streptococci bind to mucin and human pharyngeal cells through sialic acid-containing receptors. Infect Immun 2001, 69, 7402-7412, doi:10.1128/iai.69.12.7402-7412.2001.

29. McDougald, D.; Rice, S.A.; Barraud, N.; Steinberg, P.D.; Kjelleberg, S. Should we stay or should we go: mechanisms and ecological consequences for biofilm dispersal. Nature reviews. Microbiology 2012, 10, 39-50, doi:10.1038/nrmicro2695.

30. Gjermansen, M.; Ragas, P.; Sternberg, C.; Molin, S.; Tolker-Nielsen, T. Characterization of starvation-induced dispersion in Pseudomonas putida biofilms. Environmental Microbiology 2005, 7, 894-904, doi:10.1111/j.1462-2920.2005.00775.x. 